\title{
THE SHARIA HOTELS IN SURAKARTA AND YOGYAKARTA FOR WORLD CITIZENS: A LINGUISTIC ANALYSIS
}

\author{
PUTRI JULI PAMUNGKAS*, VILYALAKSTIAN CATRAMULIA** \\ *ABA Harapan Bangsa Surakarta, Email: pjuli145@gmail.com dan **ABA Harapan Bangsa Surakarta, \\ Email: vilyalakstian@gmail.com
}

\begin{abstract}
Linguistic qualitative research using appraisal theory is descriptively undertaken on the English websites of the sharia hotels in Surakarta and Yogyakarta. The data are analyzed on the basis of Appraisal Theory coined by Martin \& White (2005) relating to kinds of attitude reflected by language that are negotiated in the texts, level of engaged feelings, and social values. This research investigates the kinds of attitude reflected by language on the data sources available on the websites of the sharia hotels in Surakarta and Yogyakarta. Using document analysis technique, the research data are analyzed in the level of words in the clauses and sentences. The research found various language attitude implemented in the sharia hotels in Surakarta and Yogyakarta in attracting customers' attention. This research does not only limit itself in finding the dominant factors, but also analyzing meanings of using those attitudes.
\end{abstract}

KeY WoRDS: appraisal, sharia hotels, promotion, website, texts

\section{HOTEL SYARIAH DI SURAKARTA DAN YOGYAKARTA UNTUK WARGA DUNIA: SEBUAH ANALISIS KEBAHASAAN}

\begin{abstract}
Abstrak
Penelitian kualitatif bahasa dengan teori appraisal ini dilakukan pada berbagai situs hotel syariah berbahasa Inggris di Surakarta dan Yogyakarta secara deskriptif. Data dianalisis dengan Teori Appraisal yang dikemukakan oleh Martin \& White (2005) terkait beragam jenis sikap yang direfleksikan dengan bahasa yang dinegosiasikan dalam teks, kekuatan perasaan yang terlibat, dan nilai sosial. Penelitian ini bertujuan menemukan jenis sikap yang direfleksikan pada bahasa pada sumber data yaitu berbagai situs hotel syariah di Surakarta dan Yogyakarta. Dengan teknik analisis dokumen, data penelitian dianalisis pada tingkat kata pada klausa dan kalimat. Hasil dari penelitian ini adalah menemukan beragam sikap berbahasa yang dibangun oleh hotel-hotel syariah di Surakarta dan Yogyakarta dalam menarik perhatian konsumen. Penelitian ini tidak hanya terbatas pada memperoleh mana yang dominan, tetapi juga menganalisis makna dari penggunaan sikap itu.
\end{abstract}

KATA KunCI: appraisal, hotel syariah, promosi, situs, teks

* Naskah diterima Juli 2020, direvisi September 2020, dan disetujui untuk diterbitkan November 2020 


\section{A. Pendahuluan}

Mempunyai hubungan sejarah bersama sebagai Kerajaan Mataram Kartosuro, Surakarta dan Yogyakarta akhirnya menjadi dua wilayah yang berbeda akibat Perjanjian Giyanti pada tanggal 13 Februari 1755 yang memisahkan keduanya (Imawan, 2020; Ricklefs, 2014). Kini dua wilayah ini dikenal sebagai pusat budaya Jawa, bahkan kini menjadi tujuan wisata favorit. Selain wisatawan lokal, wisatawan asing mengunjungi tempat-tempat wisata di kedua wilayah tersebut. Untuk melengkapi kebutuhan akomodasi mereka, terutama di Surakarta dan Yogyakarta, bisnis perhotelan menjadi semarak.

Menurut Lawson (1976), hotel adalah sarana tempat tinggal umum bagi wisatawan dengan menyediakan layanan kamar, makanan dan minuman, serta kebutuhan pembayaran, dalam berbagai peringkat dan kualitas. Dengan semakin dinamis dan heterogennya wisatawan, kehadiran hotel berkembang, di antaranya, dengan adanya hotel berbasis syariah, termasuk di Surakarta dan Yogyakarta. Hotel syariah resmi hadir berlandaskan Dewan Syariah Nasional MUI, Fatwa No. 108 / DSN-MUI / X / 2016 tentang Pedoman Penerapan Pariwisata yang memuat penyediaan akomodasi berupa kamar dalam bentuk bangunan yang dapat dilengkapi dengan layanan makanan dan minuman, kegiatan hiburan dan atau fasilitas lainnya setiap hari dengan tujuan mendapatkan manfaat yang dijalankan sesuai dengan prinsip syariah, termasuk di dalamnya terdapat standardisasi MUI yang memberikan sertifikasi halal, terutama untuk makanan dan minuman.

Kemajuan teknologi internet turut mengembangkan usaha hotel syariah untuk mempromosikannya di situs (website) resminya. Layanan situs web hotel berguna untuk memberikan informasi tentang hotel dan memudahkan tamu untuk membuat reservasi. Selain itu, layanan situs resmi hotel juga berguna untuk promosi melalui media sehingga informasi yang tersedia di dalamnya dapat menambah referensi hotel untuk calon tamu (Indrayana Tirtayasa \& Paturusi, 2016). Keinginan Indonesia untuk menjadi tujuan wisata syariah dunia memberikan angin segar kepada hotel-hotel syariah dan memotivasi untuk berpromosi. Ini turut melatarbelakangi hotel-hotel syariah mengoptimalkan bahasa Inggris pada situs resminya. Hal ini menarik perhatian peneliti untuk memperolehnya sebagai data dalam penelitian ini.

Untuk menarik perhatian calon tamu, hotelhotel syariah juga tidak ketinggalan untuk memberikan kesan yang terbaik terhadap fasilitas yang dimilikinya. Cara ini diusahakan agar dapat menyentuh hati para calon tamu. Secara tidak langsung teks dinegosiasikan antar penggunanya, yaitu penulis konten dan pembaca. Martin \& White (2005) memiliki teori penilaian bahasa (language of evaluation) untuk menganalisis negosiasi tersebut. Sistem penilaian mengacu pada evaluasi yang berkaitan dengan sikap yang dinegosiasikan dalam teks, kekuatan emosi dan perasaan yang terlibat dapat diamati dalam teks, serta bagaimana nilai mengenai sesuatu atau objek dihasilkan dan disesuaikan oleh pembaca (Martin \& Rose, 2003; Martin \& White, 2005). Terdapat tiga kategori yaitu affect, judgment, dan appreciation. Penentuan kategori ini didasari oleh penggunaan kata pada suatu konteks (White, 2015: 2).

Affect adalah penilaian positif dan negatif yang berkaitan dengan perasaan tentang sesuatu yang dibicarakan atau berkaitan dengan ekspresi emosi (Fisher, 1996; Martin \& Rose, 2003; Martin \& White, 2005). Kategori ini direfleksikan melalui kata kerja yang berkaitan dengan proses emosional (melibatkan proses mental) seperti mencintai, membenci, menakuti, membujuk, tertarik, atau membosankan. Bisa juga diungkapkan dengan kata sifat yang mampu menyentuh emosi seperti senang, sedih, khawatir, percaya diri, marah, senang, tertarik, atau tidak tertarik.

Judgement adalah masalah penilaian positif dan negatif yang berkaitan dengan perilaku sesuatu yang sedang dibahas. Kategori ini disimbolkan dengan kata-kata yang merefleksikan anggapan terhadap perilaku masyarakat yang kemudian dievaluasi sebagai moral, tidak bermoral, legal, ilegal dan sebagainya. Anggapan dapat berbentuk frase kata kerja, atribut kata benda, dan kata kerja.

Appreciation adalah penilaian terhadap objek, bentuk atau proses yang meliputi reaksi, komposisi, dan penilaian. Jenis ini juga berfungsi untuk memberikan penilaian terhadap suatu kondisi. Jenis ini juga digunakan untuk mengevaluasi objek, proses, atau produk. Biasanya dalam bentuk atribut untuk objek, proses atau produk tertentu. Appreciation bisa negatif dan juga bisa positif tergantung pada dampak makna 
yang ditimbulkan. Martin \& White (2005) menyatakan bahwa istilah ini umumnya dapat dibagi menjadi reaksi kita terhadap sesuatu seperti apakah mereka menarik perhatian kita atau apakah mereka menyenangkan kita. Komposisi benda-benda ini (seimbang atau kompleks), dan nilai benda-benda ini (inovatif, asli, terjadi pada waktu yang tepat, dan sebagainya). Selanjutnya, Martin \& White (2005) menjelaskan bahwa appreciation dapat diartikan sebagai reaksi antarpersonal.

Ketertarikan penelitian terdahulu pada penentuan pola appraisal sebagaimana Nazhira et al (2016) lakukan dan dominasi kategori dari sikap berbahasa yang dibangun seperti hasil temuan Nugrahaeni (2011) pada iklan di tabloid, Nur \& Hadi (2016) pada media sosial, Binarkaheni (2019) pada laman hotel membutuhkan pengembangan. Salah satu tujuan penelitian Binarkaheni (2019) dilakukan dalam penelitian ini. Sumber data dalam penelitian ini, yaitu hotel syariah, menjadi nilai kebaruan dalam kajian industri perhotelan. Penelitian ini melengkapi Binarkaheni (2019) yang perlu mengeksplorasi keterhubungan antara pilihan kata sebagai bagian dari strategi dan konteks situasi yang dihadirkan pada media promosi laman hotel syariah.

Laman hotel menjadi perhatian bagi penelitian-penelitian di bidang kajian yang bersifat manajerial. Indrayana Tirtayasa \& Paturusi (2016) yang telah mengkaji pentingnya laman hotel untuk kegiatan promosi, sedangkan Herminingtyas (2014) menjadikan laman hotel sebagai sumber data untuk melihat pengaruh dalam peningkatan brand image. Penelitian terhadap hotel syariah ini akan memberikan kontribusi terhadap penemuan contoh prototipe kebahasaan yang dibentuk melalui teks untuk tujuan promosi.

Melalui analisis ketiga kategori di atas, dapat dilihat bagaimana penulis mengambil sikap dalam mengekspresikan ide-idenya, apakah dipengaruhi oleh minat tertentu atau tidak. Oleh karena itu, kedua peneliti ini tertarik untuk melakukan penelitian pada laman hotel syariah dengan mengambil konteks di Surakarta dan Yogyakarta melalui pendekatan teori penilaian (appraisal) bahasa tersebut.

Tujuan dari penelitian ini adalah untuk mengetahui apa saja kategori yang direfleksikan oleh kata-kata emotif dalam situs resmi hotel syariah di Surakarta dan Yogyakarta. Setelah memperoleh pengelompokan itu, peneliti menampilkan kategori yang dominan. Penelitian ini juga akan mengelaborasikan kategori yang dominan itu terhadap makna yang sedang dinegosiasikan antar pengguna teks, hingga menemukan prototipe teks yang dibangun dari pilihan kata.

\section{B. Metode Penelitian}

Penelitian ini dirancang dengan desain penelitian deskriptif kualitatif karena data berbentuk kata-kata, bukan angka (sejalan dengan Sudarwan, 2002). Menurut Moleong (2005), penelitian kualitatif berusaha memahami fenomena apa yang dialami oleh subjek penelitian seperti perilaku, persepsi, motivasi, tindakan, dan sebagainya. Hal ini kemudian dideskripsikan secara holistik dalam bentuk kata dan bahasa yang kontekstual sehingga memperoleh nilai alamiah.

Penelitian ini bersifat deskriptif-analitik karena bertujuan menggambarkan atau mendeskripsikan fenomena kebahasaan. Sutopo (2006) mengatakan bahwa penelitian kualitatif meletakkan perhatian pada deskripsi data yang berisi kata, klausa, dan kalimat. Data dalam penelitian ini adalah pada tingkat kata emotif yang melekat pada frasa, klausa, dan kalimat dalam teks di sumber data. Data tersebut kemudian dideskripsikan dengan mengidentifikasi, mengklasifikasi, dan menganalisis, terutama pada kategori penilaian bahasa dengan appraisal meliputi affect, judgement, dan appreciation. Kategori tersebut merupakan turunan dari pendekatan Linguistik Sistemik Fungsional (LSF) pada lingkup leksikogrammatikal dimana kata memberikan kontribusi dalam membentuk struktur klausa. Penilaian bahasa ini berada pada ruang lingkup fungsi pelibat (interpersonal) di antara dua lainnya dalam metafungsi bahasa yaitu pengalaman (experiential) dan tekstual (Halliday, M.A.K. \& Matthiessen, 2014; Martin \& White, 2005). Penilaian bahasa dalam appraisal menjadi alat analisis untuk mengetahui bagaimana bahasa mengartikulasikan makna interpersonal karena terdapat makna yang dinegosiasikan oleh pelibat teks (Eggins, 2004; Martin \& White, 2005).

Dalam penelitian ini, penulis menggunakan teknik sampling berlandaskan tujuan (purposive sampling). Menurut Sugiyono (2016: 85), jenis sampling ini melibatkan teknik pengambilan sampel dari sumber data didasari pertimbangan 
tertentu. Hal ini dilakukan karena tidak semua sampel memiliki kriteria yang sesuai dengan fenomena yang sedang diteliti. Kriteria untuk memenuhi sampling ini meliputi beberapa poin. Pertama, data berupa kata-kata emotif dalam frasa, klausa, dan kalimat. Hal ini tidak lepas dari lingkup leksikogrammatikal pada stratifikasi sistem bahasa dalam LSF. Kata emotif menyiratkan makna emosional yaitu makna yang muncul akibat reaksi atau sikap pembicara maupun penulis tentang atau terhadap sesuatu yang dipikirkan atau dirasakan (Sipley dalam Pateda, 2001: 101). Inilah mengapa kata emotif menghasilkan makna yang melibatkan perasaan.

Kedua, data tersebut terdapat pada sumber data berupa berbagai situs hotel syariah di Surakarta dan Yogyakarta yang dapat diakses daring. Pemerolehan data dilakukan dengan analisis dokumen yang berisi transkrip teks dari sumber data sehingga dapat diperoleh data kebahasaan, tabulasi kategori, dan menjalin keterhubungan dengan konteks dari sumber data.

Ketiga, sumber data bersama data yang dikumpulkan berasal dari rentang waktu satu bulan yaitu tanggal 1 hingga 30 Januari 2020 yang kemudian didapatkan tiga hotel syariah di Surakarta dan dua di Yogyakarta. Terdapat Syariah Hotel Solo, Aziza, dan Arini di Surakarta, kemudian Alzara dan Namira di Yogyakarta. Hotel-hotel tersebut berasal dari hasil temuan prioritas mesin pencari (search engine) populer pada rentang waktu tersebut.

\section{Hasil dan Pembahasan}

Pada bagian ini, peneliti memaparkan hasil temuan dalam penelitian dan kemudian membahasnya dengan memperoleh keterhubungan antar komponen yang didapat.

Hasil temuan dalam penelitian ini ditunjukkan dengan menampilkan hasil sebaran data emotif dalam tiga kategori sikap berbahasa meliputi affect, judgment, dan appreciation seperti yang tampak pada subbagian klasifikasi kata emotif. Pada bagian ini, peneliti memaparkan hasil temuan. Tabel sebaran data (lihat Tabel 1) digunakan oleh peneliti untuk menemukan keterkaitan antara jumlah temuan dengan konteks pada sumber data untuk menemukan dampak dari dominasi kategori yang dominan serta nilai budaya yang dibangun.

Klasifikasi Kata Emotif

\section{a. Affect}

Kata-kata emotif yang dikelompokkan sebagai affect adalah kata-kata yang melibatkan perasaan. Berikut ini adalah analisis dari klausa yang termasuk dalam kategori affect.

(1) Ideal for fun and relaxation, Sharia solo hotel is located in the Colomadu area of Solo (Surakarta).

(2) The excitement of the city center is only $2.8 \mathrm{~km}$ away.

(3) A comfort and pleasant hotel that offers affordable luxury rooms

Pada ketiga data di atas, kata-kata emotif seperti fun (keceriaan), excitement (kegembiraan), dan pleasant (ramah) melibatkan unsur perasaan. Hal ini yang sedang ditawarkan kepada para tamu sehingga para tamu tertarik untuk menginap di hotel-hotel syariah di Surakarta dan Yogyakarta. Data (1) dan (2) melibatkan perasaan positif melibatkan deskripsi lokasi, sedangkan (3) pada penampilan ruangan.

\section{b. Judgement}

Judgement adalah aspek sikap yang melibatkan evaluasi karakter atau perilaku. Jenis ini memiliki dua kategori, ada apresiasi sosial dan hukum sosial (Martin \& White, 2005). Berikut ini adalah kata yang terkandung judgement dalam sumber data:

(4) Valid for 2 person for buffet breakfast.

(5) Express check-in / check-out.

(6) good for more than 25 cars

Kata valid (berlaku) memiliki arti penilaian terhadap sesuatu yang dapat dilakukan seseorang sesuai dengan ketentuan tertentu. Dalam hal ini adalah berlakunya ketentuan layanan makan pagi untuk dua orang. Sedangkan express (cepat) adalah penilaian pada proses check-in atau checkout yang dilakukan dari resepsionis ke tamu. Sedangkan good (baik) menilai ketepatan penyediaan penggunaan fasilitas terhadap kebutuhan tamu, yaitu terkait kapasitas area parkir.

\section{c. Appreciation}

Appreciation digunakan untuk mengevaluasi hal-hal, proses, atau produk. Penghargaan memiliki dua kategori, yaitu penghargaan positif dan penghargaan negatif. Berikut ini adalah beberapa contoh yang diperoleh dari data.

(7). Ideal for fun and relaxation

(8) Syariah Hotel Solo offers impeccable service 
(9) For the comfort and convenience of guests

(10) free wi-fi in all rooms

(11) beautifully designed guest rooms

Kata-kata seperti relaxation (relaksasi), impeccable (sempurna), comfort (kenyamanan), convenience (kemudahan), free (gratis), beautifully (dengan indah) adalah bentuk apresiasi yang dihadirkan pada fasilitas yang ditawarkan hotel. Penghargaan dijunjung atas fasilitas yang dimilikinya.

Sikap memberikan apresiasi ini memiliki jumlah yang secara signifikan lebih banyak dibandingkan kategori yang lainnya. Data nomor (7) sampai (11) adalah sebagian dari total 64 data emotif lainnya.

Apresiasi diberikan pada fasilitas, perlengkapan, dan penampilan hotel. Selain itu, apresiasi juga dilakukan pada lingkungan di sekitar hotel. Contohnya dalam temuan berikut.

(12) It is within easy access to the Airport Adi Sumarmo

(13) A comfort and pleasant hotel that offers affordable luxury rooms to accompany your journey to enjoy Gunungkidul's fascinating landscape

Data nomor (12) dan (13) adalah bentuk apresiasi yang melibatkan lingkungan di sekitar hotel. (12) menunjukkan kemudahan akses (easy access) ke bandara. Sedangkan (13) menunjukkan kenyamanan (comfort) hotel dalam menemani perjalanan menikmati (enjoy) pemandangan Gunung Kidul yang mengagumkan (fascinating).

Contoh di atas masing-masing dilakukan oleh hotel syariah di Surakarta dan Yogyakarta. Cara ini menarik agar hotel tidak berorientasi pada diri (self-oriented) saja, namun juga memberdayakan sekitarnya. Hotel syariah menjadi bagian dari kegiatan pariwisata dan menikmati keindahan pemandangan di wilayah itu.

\section{Appreciation Sebagai Strategi}

Semua kategori dalam sikap berbahasa dijalankan oleh hotel-hotel syariah di Surakarta dan Yogyakarta melalui situs resminya. Melihat total dari seluruh sebaran data pada kategorinya, didapatkan rincian sebagaimana tampak pada Tabel 1 di bawah ini.
Tabel 1. Sebaran kategori sikap dalam teks

$$
\text { Sikap Berbahasa Total }
$$

\begin{tabular}{lr}
\hline Affect & 3 \\
Judgement & 3 \\
Appreciation & 64 \\
Jumlah & 70
\end{tabular}

Sikap berbahasa didominasi oleh appreciation. Terdapat perbedaan jumlah yang signifikan antara hasil temuan appreciation dibandingkan affect dan judgement. Menurut Martin dan White (2005: 4344), affect berkaitan dengan unsur perasaan, judgement dengan etika, dan appreciation dengan estetika. Temuan ini menunjukkan bahwa orientasi pembuat teks, dari pihak hotel, menekankan pada unsur estetika. Dalam hal ini, sikap penghargaan digunakan untuk dua kepentingan sekaligus. Pertama, penghargaan digunakan sebagai sarana untuk menggambarkan realitas fasilitas yang ditawarkan oleh hotel syariah di Surakarta dan Yogyakarta. Kedua, setelah deskripsi item ditampilkan, cara ini juga digunakan untuk membentuk citra layanan di hotel syariah. Semua kamar didekorasi secara menarik didukung fasilitas yang modern, tersedianya akses internet gratis, dan beragam kenyamanan lainnya adalah contoh data yang menunjukkan bahwa apresiasi dapat digunakan untuk menggambarkan fasilitas dan layanan di hotel syariah. Didukung dengan visualisasi fotofoto, para calon tamu dicoba untuk dihadirkan dalam suasana itu. Tujuan utama dari apresiasi ini adalah dalam membentuk kesan atau gambaran kepada tamu. Nilai yang dibangun dari jenis sikap ini difasilitasi oleh penggunaan kalimat yang menarik perhatian dan meningkatkan imajinasi. Para calon tamu juga berperan sebagai pembaca teks. Penggunaan beragam kata pada kalimat yang berimplikasi dengan keindahan membuat informasi diingat dan menarik karena menjadi bagian dari kebutuhan tamu.

\section{Sikap Berbahasa yang Relevan}

Dominasi appreciation pada hasil temuan dalam penelitian ini bukanlah tanpa alasan. Hal ini pun dapat dijelaskan secara ilmiah dalam konteks kebahasaan. Mengingat Martin dan White 
(2005: 43-44), informasi terkait penginapan yang bersih, indah, nyaman, dan berkualitas adalah idaman bagi tamu, termasuk bagi para calon tamu hotel syariah merupakan aspek estetika yang sedang ditekankan. Ini yang membuat sikap appreciation mendominasi. Teori appraisal Martin \& White (2005) yang digunakan untuk menganalisis data dalam penelitian ini menghasilkan jumlah sebaran data pada tiga subkategori sikap berbahasa. Pola yang diperoleh ini merupakan refleksi sebagaimana Vijay (2014) katakan tentang karakteristik aktivitas promosi yang kemudian digolongkan dalam product appraisal. Dari temuan ini, dapat diperoleh karakteristik sikap berbahasa yang digunakan dalam promosi sektor jasa hotel syariah. Hasil temuan ini relevan dengan konteks dimana data kebahasaan itu melekat pada suatu konteks. Hal ini dapat dibandingkan dengan temuan-temuan pada penelitian lain. Misalnya, dominasi kategori apresiasi yang ditemukan oleh Nugrahaeni (2011) pada iklan produk dan jasa pada tabloid Nova. Namun pada konteks yang lain menunjukkan dominasi kategori yang berbeda, seperti dominasi affect dalam temuan Nur dan Hadi (2016) pada komentar-komentar para pengguna di akun Instagram suatu penyedia produk.

Temuan dalam penelitian ini dapat menjadi prototipe pola kebahasaan yang khusus pada sektor tertentu yang kemudian dapat dibandingkan dengan sektor yang lain untuk kelanjutan penelitian berikutnya. Aktivitas berbahasa menjadi terpola, namun bisa menjadi referensi bagi para pengusaha baru untuk mengetahui apa saja yang perlu disampaikan kepada konsumen potensialnya.

\section{Kesimpulan}

Penelitian ini memberikan referensi pada analisis teks dalam melihat sikap berbahasa yang dibangun. Temuan dalam penelitian ini memberikan kontribusi dalam kajian sosial kebahasaan bahwa setiap ekspresi bahasa yang diungkapkan membawa makna yang terkonstruksi sesuai dengan tujuannya, baik disadari maupun tidak. Bahasa menjadi medium untuk berjalannya proses sosial.

Meskipun ketiga subkategori sikap berbahasa muncul dari hasil temuan, namun sebarannya tidak merata, bahkan secara signifikan didominasi appreciation. Tetapi dari ketidakrataan tersebut diperoleh prototipe teks dalam konteks promosi daring hotel syariah pada sumber data penelitian ini. Pola yang muncul menjadi tekstur penyampaian teks promosi daring hotel syariah kepada pembaca atau calon tamu hotel. Penggunaan bahasa Inggris pada promosi daring ini menunjukkan sikap optimistis bahwa hotel syariah, khususnya di Surakarta dan Yogyakarta, mampu bersaing dalam ranah pariwisata global.

Pada konteks bisnis hotel syariah, sikap berbahasa penting dibangun sehingga mampu memberikan daya pikat, bahkan dalam menghadirkan konsumen agar mampu memperoleh gambaran terhadap fasilitas yang disediakan. Pada akhirnya, itu semua memberikan manfaat bagi kedua belah pihak. Bagi konsumen, mereka memperoleh apa yang dibutuhkan. Sedangkan bagi pemilik usaha, mereka menunjukkan komitmen terhadap ketersediaan layanan dan membangun citra positif.

\section{UCAPAN TERIMAKASIH}

Kami mengucapkan terima kasih kepada Direktur dan Pimpinan Lembaga Penelitian dan Pengabdian kepada Masyarakat (LPPM) di ABA Harapan Bangsa Surakarta yang telah memberikan fasilitas penggunaan laboratorium bahasa untuk memperoleh dan mengolah data. Terima kasih juga kami ucapkan kepada dewan redaksi dan Mitra Bestari (reviewer) Jurnal Dialog, Sekretariat Badan Litbang dan Diklat Kementerian Agama RI yang mempublikasikan penelitian ini sehingga menambah referensi kajian sosial kebahasaan di masyarakat. 
Binarkaheni, S. (2019). A Language Appraisal of Hotel Web Pages in Indonesia Five Starred Hotels: Interpersonal Meaning. NOBEL: Journal of Literature and Language Teaching, 10(1). https://doi.org/10.15642/ nobel.2019.10.1.52-70

Eggins, S. (2004). An Introduction to Systemic Functional Linguistics. Continuum.

Fisher, M. (1996). Performance Appraisal. kogan page.

Halliday, M.A.K., \& Matthiessen, C. M. I. M. (2014). Halliday's Introduction to Functional Grammar. Routladge.

Herminingtyas, R. (2014). Analisis Layanan Website Sebagai Media Promosi, Media Transaksi dan Media Informasi Dan Pengaruhnya Terhadap Brand Image Perusahaan Pada Hotel Ciputra di Kota Semarang. Jurnal STIE Semarang.

Imawan, D. H. (2020). Pesantren Mlangi; Poros Spiritual Intelektual Islam di Yogyakarta Abad XVIII - XIX M. Millah: Jurnal Studi Agama, 19(2), 225-246. https://doi.org/ 10.20885/millah.vol19.iss2.art3

Indrayana Tirtayasa, P. P., \& Paturusi, S. A. (2016). Penggunaan Situs Web Hotel Dan "Online Travel Agency" Sebagai Media Promosi Dan Penjualan Bagi Hotel Melati di Ubud. Jurnal Master Pariwisata (JUMPA), 3(1), 60-71. h t t p s://d o i.org / 10.24843 / jumpa.2016.v03.i01.p05

Lawson, F. (1976). Hotels, Motels, And Condominius/ : Design, Planning, And Maintenance. Architectural Press.

Martin, J. ., \& Rose, D. (2003). Working With Discouse: Meaning beyond the clause. continuum.

Martin, J. R., \& White, P. R. R. (2005). The Language of Evaluation: Appraisal in English. Palgrave Macmillan.

Moleong, L. (2005). Metodology Penelitian Kualitatif. PT. Remaja Rosdakarya.
Nazhira, R., Sinar, S., \& Suriyadi. (2016). Appraisal Sikap dalam Teks Berita Surat Kabar Nasional. Jurnal Tutur, 2(1), 1-14.

Nugrahaeni, Y. (2011). Sistem Appraisal Pada Teks Iklan Komersial di Tabloid Nova. Parole: Journal of Linguistics and Education, 2(1), 4558. $\quad$ https://doi.org/10.14710/ parole.v2i1April.1562

Nur, A. M., \& Hadi, A. S. (2016). Realisasi Appraisal dalam Aspek Attitude pada Media Online Instragram. Jurnal Sasindo Unpam.

Pateda, M. (2001). Semantik Leksikal. Rineka Cipta.

Ricklefs, M. C. (2014). Babad Giyanti/ : Sumber Sejarah dan Karya Agung Sastra Jawa. Jumantara, 5(2), 11-25.

Sudarwan, D. (2002). Menjadi Peneliti Kualitatif Rancangan Metodologi, Presentasi, dan Publikasi Hasil Penelitian untuk Mahasiswa dan Penelitian Pemula Bidang Ilmu Sosial, pendidikan dan Humaniora. Remaja Rosdakarya.

Sutopo, H. (2006). Metodologi Penelitian Kualitatif: Dasar Teori dan Penerapannya dalam Penelitian. Universitas Sebelas Maret.

Vijay, B. (2014). Worlds of Written Discourse: A Genre-Based View. Bloomsbury Publishing Plc.

White, P. R. R. (2015). Appraisal Theory. In The International Encyclopedia of Language and Social Interaction (pp. 1-7). John Wiley \& Sons, Inc. 
184 Hotel Syariah di Surakarta ... 
